during efforts at swallowing. The skiagram (Fig. 2) was taken with the same apparatus as in the preceding case and with an exposure of 60 seconds. The boy was then transferred to the Southern Hospital and there under an anæsthetic Mr. Newbolt could just reach the top of the foreign body through the mouth with his finger. Without any difficulty he then managed to catch hold of it with a pair of strong forceps and to remove it. The boy made an uninterrupted recovery.

Liverpool.

\section{Clinital a diptes:}

\section{MEDICAL, SURGICAL, OBSTETRICAL, AND THERAPEUTICAL.}

\section{NOTE ON A CASE OF MENINGO-MYELOCELE.}

By JaMes BURNeT, M.A., M.B., Ch.B. Edin.

ON Jan. 29th, 1901, at 11.45 P.M., I was called to attend a woman in labour. It was her third pregnancy. She had had twins, who died from "decline" six months after birth. Her next child, born four years ago, is alive and healthy. About 18 months ago she had an abortion at the third month and was ill for a long time afterwards. In May of last year I saw her and treated her for constipation and anæmia, with the result that she improved considerably in health. About the end of December she sent for me, as she began to complain of a severe pain in the suprapubic region and over the right iliac fossa. She looked then very much ran down. I prescribed for her, but she was unable to leave her bed much until labour set in on Jan. 29th. The presentation was a vertex one. There was some delay in the birth of the head, which was larger than the average. When born the child-a female-was asphyxiated, and gave evidence of convulsive twitchings in both arms and legs. Artificial respiration was performed, and the child soun revived and cried in a feeble manner. On examination I found a tumour situated in the lumbar region. It measured fully three and a half inches in length and two inches in breadth. It was sessile, and presented a wellmarked central cicatrix. There was talipes of both feet, with some rigidity of the knee joints. The knee reflexes appeared to be absent. The surface of the tumour was only partially covered by skin. The sac wall was very thin. The tumour was carefully dressed and protected from external pressure. In spite of our efforts, however, rupture was evident on the third day and the child died quietly on the morning of the seventh day, having previously refused the breast. Two days prior to death I observed considerable mottling of the face and trunk, with depression of the fontanelle. Examination of the heart was entirely negative. No postmortem examination was obtained, which I greatly regret.

The mother is a very neurotic woman, constipated and anæmic, always taking a very despondent view of life. No doubt these facts help to explain this early failure of development. I may add that the placenta and cord were perfectly normal.

Edinburgh.

\section{A CASE OF IRREDUOIBLE DORSAL DISLOCATION} OF THE PROXIMAL PHALANX OF THE INDEX FINGER.

By C. F. M. ALTHORP, M.B. LOND., SURGEON TO THE BRADFORD ROYAL INFIRMARY.

ON July 6th, 1900, a youth, aged 16 years, whilst at work in a warehouse in Bradford, fell off a ladder, alighting on the right hand and dislocating the proximal phalanx of the index finger. When seen at the infirmary soon after the accident the right index finger presented the following appearance. The base of the proximal phalanx formed a prominence on the dorsum of the hand, the head of the metacarpal bone projected into the palm, and the finger was shortened and there was limitation in movement. Attempts at reduction by manipulation were made by several of $\mathrm{my}$ colleagues as well as by myself, but without success. Gas, followed by ether was given and after the skin had been thoroughly cleansed an incision, an inch in length, was made over the radial side of the joint. The soft structures were drawn apart and the joint was freely exposed. A strong fibrous band, the glenoid ligament, was seen stretched over the head of the metacarpal bone, preventing reduction of the dislocation. The ligament was partly divided with the knife, and then with a blunt elevator I levered the stretched band over the articular end of the metacarpal bone. At once the dislocation was reduced. The wound was closed, without drainage, and when dressed a few days afterwards was found to be healed. Massage and passive movements were employed, the stiffness gradually disappearing.

In December, 1900, six months after the operation, the patient was shown to the members of the Bradford MedicoChirurgical Society. There were some thickening around the joint and slight limitation in extreme flexion. He had perfect use of the finger and could write as well as before the accident.

The case is of interest as illustrating the fact that in these dislocations (not only of the thumb but also of the fingers) it is the glenoid ligament which is the mechanical obstacle to reduction. By freely exposing the joint I was able to see the glenoid ligament stretched over the head of the metacarpal bone.

Bradford.

\section{DIABETES MELLITUS IN A OHILD, WITH OOMA.}

By J. G. McNadghton, M.D., M.R.C.P. Edin.

THE fact that diabetes mellitus in children, with rapid coma, is comparatively rare may make this case worthy of record.

I was called to see a girl, aged five years, on Jan. 21st, 1901, and obtained the following history. Wasting had been observed for only four weeks, and three weeks previously the mother had observed that the child was drinking large quantities of water. She would send her older sister for "drinks" during the night. At the same time she was passing more urine than usual. She complained of nothing else and played about as usual. No increase of appetite was observed. Three weeks before both ears discharged for one day, but there had been no discharge since. On examination on Jan. 21st the pulse was 116 and small ; the temperature was $97.6^{\circ} \mathrm{F}$. She was restless and difficult to rouse when spoken to. The skin was dry. The pupils were equal and there had been no twitching. She complained of no pain. The urine was straw-coloured and frothy, and on being tested it was found to contain sugar and albumin. The lungs and heart were normal.

On Jan. 22nd I was summoned at 7 A.M. The patient had vomited several times during the night. During the 24 bours she had passed over 20 ounces of urine. She was in great distress and complained of pain above the umbilicus. There was great dyspnoea, the respirations being 38 per minute. The lips, face generally, and limbs, especially the feet, were cyanosed; one tenth of a grain of codeia every three hours gave her some relief. The urine passed contained 6 per cent. of sugar and 3 per cent. of albumin. The patient was seen at 4 P.M.; there were even greater dyspncea and cyanosis, and she was gradually passing into a comatose state. The coma gradually deepened and she died at $3 \mathrm{~A} . \mathrm{M}$. on the next day.

The progress of the case was apparently very rapid, no urgent mischief beirg suspected till two days before death. The parents are intelligent people and careful of their children. The family history was not good. The mother has had five children and the eldest, an imbecile, died when about nine years of age. An aunt of the mother died from diabetes, and a sister of the father died from the same disease when over 50 years of age.

No examination of the body was allowed. It is possible that there may have been some change in the base of the brain, but one could get no history of irritation of cranial nerves, the only fact elicited being the discharge from the ears.

On Feb. 21st the mother of the child sickened with influenza. When seen for the first time on the 22nd the temperature was $100.4^{\circ}$ and the pulse was 98 . On the same evening she became acutely maniacal and she died 36 hours later in the same state. This note may be of interest, taken in connexion with Dr. Howship Dickinson's Baillie lecture in THE LANCE'T of Feb. 2nd, p. 299.

Turriff, N.B. 